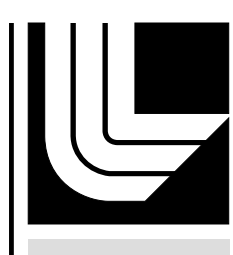

LAWRENCE LIVERMORE N A T IO N A L LABORATORY

\title{
Pyrolytic Removal Of The Plastic Mandrel From Sputtered Beryllium Shells
}

R. C. Cook, S. A. Letts, S. R. Buckley, E. Fearon

August 3, 2005

Fusion Science And Technology 
This document was prepared as an account of work sponsored by an agency of the United States Government. Neither the United States Government nor the University of California nor any of their employees, makes any warranty, express or implied, or assumes any legal liability or responsibility for the accuracy, completeness, or usefulness of any information, apparatus, product, or process disclosed, or represents that its use would not infringe privately owned rights. Reference herein to any specific commercial product, process, or service by trade name, trademark, manufacturer, or otherwise, does not necessarily constitute or imply its endorsement, recommendation, or favoring by the United States Government or the University of California. The views and opinions of authors expressed herein do not necessarily state or reflect those of the United States Government or the University of California, and shall not be used for advertising or product endorsement purposes. 


\title{
Pyrolytic Removal of the Plastic Mandrel from Sputtered Beryllium Shells
}

\author{
Robert C. Cook, Stephan A. Letts, Steven R. Buckley, Evelyn Fearon \\ Lawrence Livermore National Laboratory \\ Livermore, CA 94550
}

\begin{abstract}
An engineering model is presented for the removal of the plastic mandrel from the inside of a sputtered Be shell. The removal is accomplished by forcing heated air in and out of the 4 to $5 \mu \mathrm{m}$ laser drilled fill hole in the capsule wall by cycling the external pressure between 2 and $5 \mathrm{~atm}$. The plastic is combusted to $\mathrm{CO}_{2}$ and $\mathrm{H}_{2} \mathrm{O}$ by this exposure, thus removing the mandrel. Calculations are presented to evaluate the various parameters in the approach. Experimental confirmation of the effectiveness of the removal is shown.
\end{abstract}




\section{Introduction.}

The current point design for the first ignition shots on the National Ignition Facility (NIF) ${ }^{1}$ in 2010 uses a 2-mm Be capsule with Cu-doped layers in the $\sim 160 \mu \mathrm{m}$ thick wall. ${ }^{2}$ These capsules are made by magnetron sputtering of Be onto spherical plastic mandrels. ${ }^{3}$ The $\mathrm{Cu}$-dopant level is controlled by varying the power to a small $\mathrm{Cu}$ sputter gun also in the system. Using these techniques capsules with the proper wall thicknesses and $\mathrm{Cu}$-doping profiles have been prepared.

The internal plastic mandrel is problematic, however, partly from a design point of view but more practically because the thermal coefficient of expansion (in this case better stated contraction) for Be is much less than for plastic, ${ }^{4}$ and these shells must be fielded at $\sim 18^{\circ} \mathrm{K}$. At this temperature it is likely that the plastic shell will pull away from the Be wall and "rattle about" inside, clearly not acceptable. Thus the plastic mandrel must be removed.

Our approach is as follows. A small hole is laser drilled through the capsule wall including the internal plastic shell. ${ }^{5}$ This hole needs to be drilled for filling, thus doesn't represent an unnecessary perturbation the capsule. Through this hole we force air (or in principle pure oxygen) by cycling the external pressure around the capsule while heating to $\sim 500^{\circ} \mathrm{C}$. At this temperature the plastic is burned to $\mathrm{CO}_{2}$ and $\mathrm{H}_{2} \mathrm{O}$, leaving the Be shell empty.

In the next section we review the stoichiometric requirements for the complete combustion of the plastic mandrel as well as the flow and cycling requirements necessary to achieve the required stoichiometry. In the following experimental section we explain how our approach has been executed in the laboratory. The results section shows radiographic evidence of mandrel removal, and a discussion section that follows considers primarily the issues of beryllium oxidation during the process and evidence of a very small residue left behind.

\section{Model.}

There are two questions we want to address in this section, one is the required stoichiometry for combustion of the mandrel, i.e. how many moles of $\mathrm{O}_{2}$ need to be supplied, and the second is the time dependence of getting the $\mathrm{O}_{2}$ into the shell and combustion products $\left(\mathrm{CO}_{2}\right.$ and $\left.\mathrm{H}_{2} \mathrm{O}\right)$ out.

A typical plastic mandrel ${ }^{6}$ is $\sim 2 \mathrm{~mm}$ in diameter with a wall thickness of $\sim 14 \mu \mathrm{m}$, and is composed of glow discharge polymer (GDP) whose density is $1.05 \mathrm{~g} / \mathrm{cm}^{3}$ and whose empirical formula is $\mathrm{CH}_{1.3}$. Thus the mass of a typical mandrel is $\sim 0.18 \mathrm{mg}$, which is $1.4 \times 10^{-5}$ moles of $\mathrm{CH}_{1.3}$. One can write the combustion of GDP as

$$
\mathrm{CH}_{1.3}+1.325 \mathrm{O}_{2} \rightarrow \mathrm{CO}_{2}+0.65 \mathrm{H}_{2} \mathrm{O}
$$

thus $1.4 \times 10^{-5}$ moles of $\mathrm{CH}_{1.3}$ requires $1.8 \times 10^{-5}$ moles of $\mathrm{O}_{2}$. Of course this is the minimum, stoichiometric amount, in reality much more may be needed. 
The void volume of a shell is about $4 \times 10^{-3} \mathrm{~cm}^{3}$, if this was air at one atmosphere and $500{ }^{\circ} \mathrm{C}\left(773^{\circ} \mathrm{K}\right)$ there would be $6.6 \times 10^{-8}$ moles of air or about $1.3 \times 10^{-8}$ moles of $\mathrm{O}_{2}$. Thus to match the stoichiometry requirement the shell would have to be filled with fresh air $1.8 \times 10^{-5} / 1.3 \times 10^{-8}=1400$ times. If we can do this once a minute then this represents less than $25 \mathrm{hr}$. Clearly this is at best an approximate calculation.

Combustion may not be instantaneous, thus some multiple of 1400 exchanges may be necessary. However we can also in principle use pure oxygen to decrease the number of exchanges by a factor of 5 , and also we can cycle higher pressure gas in and out of the shell, significantly reducing the number of cycles required as shown below. At this point all we have demonstrated is that the approach is feasible assuming a combustion rate that uses a reasonable amount of the supplied oxygen per cycle.

There is a second concern, however, that needs to be addressed. The approach is to pump hot air in and out of the shell through a small diameter hole. For the ignition capsule this hole will be about $150 \mu \mathrm{m}$ long and 4-5 $\mu \mathrm{m}$ in diameter. Do the dimensions of the hole significantly impact the cycling rate?

To answer this we will model the flow of gas through the hole with the Poiseuille formula for fluid flow in a pipe:

$$
\frac{d V}{d t}=\frac{\pi a^{4}}{8 \eta w} \Delta P
$$

where $d V / d t$ is the time rate of flow of an incompressible fluid of viscosity $\eta$ through a pipe of radius $a$ and length $w$ due to a pressure drop $\Delta P$. The assumption is that the fluid is Newtonian; we'll come back to this point later. Clearly a gas is not incompressible, but it is not clear what role that plays here so we'll ignore it. In order to use this expression we will need the viscosity of the flowing gas. The gas going in, air or perhaps pure $\mathrm{O}_{2}$, is different than the gas coming out, $\mathrm{CO}_{2}, \mathrm{H}_{2} \mathrm{O}$, and if we use air $\mathrm{N}_{2}$, so in principle the viscosity will be different going in and out. Further the viscosity is a function of the pressure and temperature. However, we will neglect all of these factors and use as $\eta$ the gas viscosity of air, as a function of temperature. ${ }^{7}$ In the spirit of this model calculation this is a reasonable assumption, particularly if we use air which is $80 \%$ $\mathrm{N}_{2}$. First the pressure dependence of $\eta$ is very small at elevated temperature near 1 atm, for $\mathrm{N}_{2}$ at $300{ }^{\circ} \mathrm{C} \eta$ equals 28.6 and $28.7 \mu \mathrm{Pa}$-s at 1 and $10 \mathrm{~atm}$. The gas type dependence is a little larger; at $300{ }^{\circ} \mathrm{C}$ and $1 \mathrm{~atm}$ the values of $\eta$ for $\mathrm{N}_{2}$ and $\mathrm{O}_{2}$ are 28.6 and $34.0 \mu \mathrm{Pa}$-s. The values for $\mathrm{H}_{2} \mathrm{O}$ and $\mathrm{CO}_{2}$ at $300{ }^{\circ} \mathrm{C}$ are about 20.3 and $27.0 \mu \mathrm{Pa}$-s, certainly in the same range. In our apparatus we vary the external pressure using a solenoid valve that alternately applies pressure and vents the furnace tube; we will assume in what follows that these variations in pressure are "instantaneous". The external pressure we will call $P_{\text {out }}$, the pressure inside the shell will be called $P_{\text {in }}$. It is the time dependence of $P_{\text {in }}$ that we want to calculate as a function of the hole parameters and external pressure cycling time.

To set up the problem let us define 


$$
\Delta P=P_{\text {out }}-P_{\text {in }},
$$

and we'll group the constants as $A$ :

$$
A=\frac{\pi a^{4}}{8 \eta w}
$$

so that

$$
\frac{d V}{d t}=A \cdot\left(P_{\text {out }}-P_{\text {in }}\right)
$$

Now lets look at what is really meant by $d V / d t$. In a time $d t$ a volume of gas $d V$ is delivered either into or out of the capsule, depending on the sign of $\Delta P$. Below we will solve these two cases separately, but before proceeding lets look more closely at how this $d V$ affects the internal pressure of the capsule. As written, eq 5 says that gas flow in is a positive $d V$; gas flow out is a negative $d V$ ( $P_{\text {in }}>P_{\text {out }}$, thus $\Delta P$ is negative). In order to look at the internal pressure of the capsule, it is useful to think in terms of moles, $n$, going in or out.

Flow out. For a $d V$ as defined above, it is clear for flow out that

$$
\frac{d V}{V_{\mathrm{sh}}}=\frac{d n}{n_{\mathrm{sh}}}
$$

where $n_{\mathrm{sh}}$ is the total number of moles of gas in the shell and $d n$ is defined like $d V$ so that gas flow out gives a negative $d n$ and $d V$. Our objective is to get $d V / d t$ in terms of $P_{\text {in. }}$ Clearly

$$
\frac{d V}{d t}=\frac{d n}{d t} \cdot \frac{V_{\mathrm{sh}}}{n_{\mathrm{sh}}}
$$

and

$$
n_{\mathrm{sh}}=\frac{P_{\mathrm{in}} V_{\mathrm{sh}}}{R T} .
$$

From the point of view of the internal pressure of the shell

$$
\frac{d n}{d t}=\frac{d P_{\text {in }}}{d t} \cdot \frac{V_{\text {sh }}}{R T}
$$

where $R$ is the gas constant. Thus using eqs 7-9, eq 5 becomes 


$$
\frac{d V}{d t}=\frac{d n}{d t} \cdot \frac{V_{\mathrm{sh}}}{n_{\mathrm{sh}}}=\left(\frac{d P_{\mathrm{in}}}{d t} \cdot \frac{V_{\mathrm{sh}}}{R T}\right) \cdot\left(\frac{V_{\mathrm{sh}}}{P_{\mathrm{in}} V_{\mathrm{sh}} / R T}\right)=A \cdot\left(P_{\mathrm{out}}-P_{\mathrm{in}}\right)
$$

or

$$
\frac{d P_{\text {in }}}{d t}=\frac{A \cdot P_{\text {out }}}{V_{\text {sh }}} \cdot P_{\text {in }}-\frac{A}{V_{\text {sh }}} \cdot P_{\text {in }}{ }^{2}
$$

The solution to this differential equation is

$$
P_{\text {in }}(t)=\frac{1}{\frac{1}{P_{\text {out }}}+\left(\frac{1}{P_{\text {in }}(0)}-\frac{1}{P_{\text {out }}}\right) \cdot e^{-\frac{A \cdot P_{\text {out }} \cdot t}{V_{\text {sh }}}}} .
$$

Flow in. What about flow into the shell, when $P_{\text {out }}>P_{\text {in }}$ ? Here the number of moles is controlled by the external pressure, $P_{\text {out }}$, which we will assume is constant during the flow. Here

$$
\frac{d V}{d t}=\frac{d n}{d t} \cdot \frac{R T}{P_{\text {out }}}
$$

so eq 5 becomes

$$
\frac{d n}{d t} \cdot \frac{R T}{P_{\text {out }}}=A \cdot\left(P_{\text {out }}-P_{\text {in }}\right)
$$

but eq 9 still holds in the shell so we have with rearrangement

$$
\frac{d P_{\text {in }}}{d t}=\frac{A \cdot P_{\text {out }}^{2}}{V_{\text {sh }}}-\frac{A \cdot P_{\text {out }}}{V_{\text {sh }}} \cdot P_{\text {in }} .
$$

The solution to this is

$$
P_{\text {in }}(t)=P_{\text {out }}+\left(P_{\text {in }}(0)-P_{\text {out }}\right) \cdot e^{-\frac{A \cdot P_{\text {out }}}{V_{\text {sh }}} \cdot t} .
$$

As noted above the use of the Poiseuille expression assumes laminar flow. This is generally true if the Reynolds Number,

$$
\operatorname{Re}=\frac{2 a \bar{v} \rho}{\eta},
$$


where $a$ and $\eta$ are defined as above, $\rho$ is the density of the gas and $\bar{v}$ is the average flow velocity, is less than 2000. To get $\bar{v}$ we'll simply take the net volume rate of flow from eq 2 (Poiseuille equation) and divide by the hole cross-section to give

$$
\bar{v}=\frac{a^{2} \Delta P}{8 \eta w} .
$$

Thus for a value of $a=3 \mu \mathrm{m}(d=6 \mu \mathrm{m}), \Delta P=1 \mathrm{~atm}, \eta=36.2 \mu \mathrm{Pa}$-s (value for air at 500 ${ }^{\circ} \mathrm{C}$ ), $w=150 \mu \mathrm{m}$, and $\rho=3.59 \times 10^{-4} \mathrm{~g} / \mathrm{cm}^{3}$ (value for air at $500{ }^{\circ} \mathrm{C}$ and $1 \mathrm{~atm}$ ) we find that $\operatorname{Re}=1.25$, clearly in the laminar regime.

Let's briefly look at simple cases to get a sense of the potential restriction due to gas flow issues. The effect of hole diameter is the most significant, the value of $A$ varying as the 4th power of the hole diameter. To get a feeling for the magnitude of the effect, we plot in Figure 1 the increase in internal pressure as a function of hole diameter for a capsule with an initial internal pressure of $2 \mathrm{~atm}$ and a constant external pressure of $5 \mathrm{~atm}$. The calculation is for air at $500{ }^{\circ} \mathrm{C}$ and a hole length of $150 \mu \mathrm{m}$. Clearly the flow through small diameters does play a role and needs to be considered.

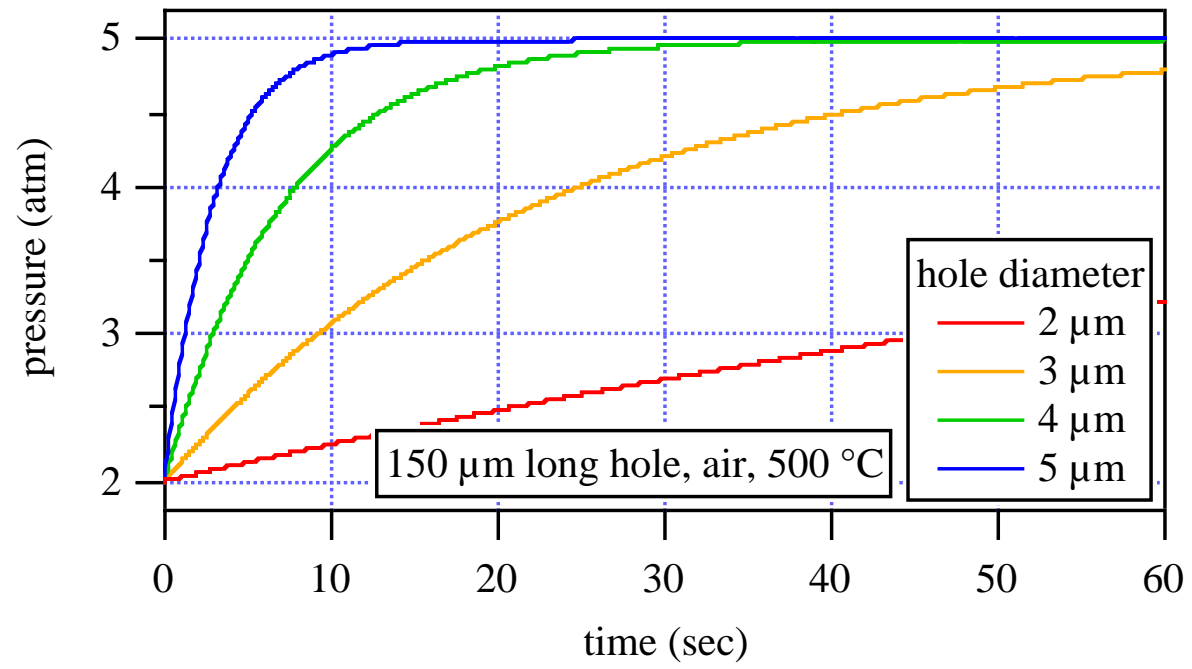

Figure 1. The effect of hole diameter on time dependence of gas flow into the shell is shown.

What we are really interested in is the net flow of air into and out of the shell per unit time, since it is this that will effect the thermal decomposition of the plastic mandrel. We will assume that oxidation is very fast, at least on the time scale of pumping. Further we will not consider that more moles of gas are produced during oxidation than we started with (see eq 1), in part because they are quite close. We will simply determine how long it takes to put $1.8 \times 10^{-5}$ moles of $\mathrm{O}_{2}\left(0.9 \times 10^{-4}\right.$ moles of air $)$ into the shell by varying the external pressure.

Lets first look at a variation between 2 and $5 \mathrm{~atm}$, which we achieve with the apparatus described in the experimental section below, as a function of frequency. In Figure 2 we show the internal capsule pressure for four different pump frequencies. In 
each case the starting internal capsule pressure was $2 \mathrm{~atm}$ of air, the imposed external pressure was alternated between 2 and $5 \mathrm{~atm}$ of air, the gas temperature was $500{ }^{\circ} \mathrm{C}$ and the hole had a diameter of $4 \mu \mathrm{m}$. There are several things to notice. First there is a start up time of a few cycles before there is regularity. This is because the pressure in the shell never again drops to $2 \mathrm{~atm}$ after the cycling begins. Second, and more important, is that because the flow through the hole is restricted, at higher frequencies the amount of gas that actually gets pumped in and out decreases per pump cycle. However we are really interested in moles of gas exchanged per time, and thus a smaller exchange per cycle may be acceptable since there will be more cycles per time.

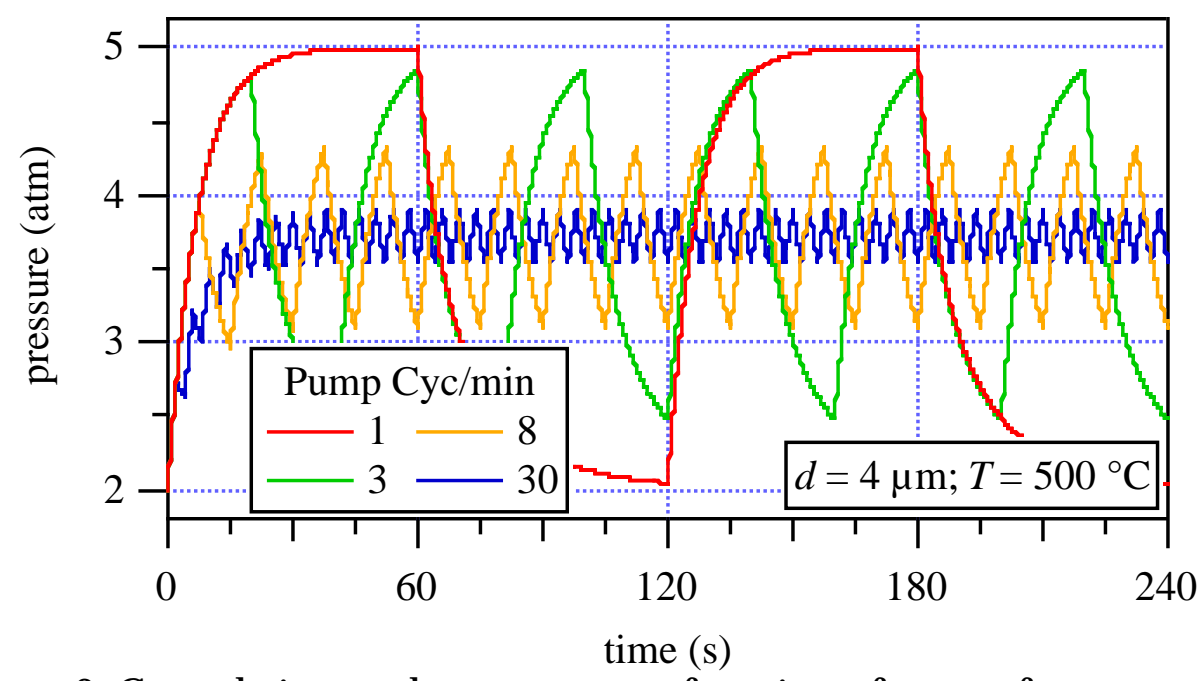

Figure 2. Capsule internal pressure as a function of pump frequency.

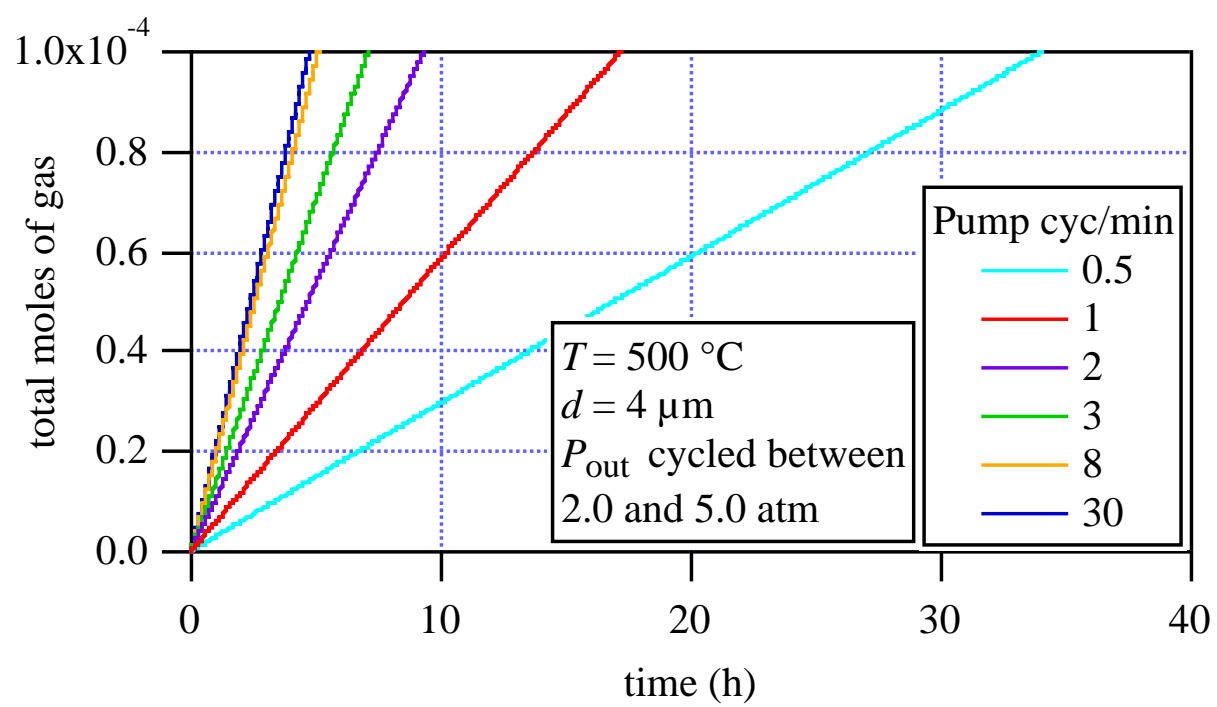

Figure 3. Moles of fresh gas delivered as a function of time for different cycling rates. It would take about $0.9 \times 10^{-4}$ moles of air to decompose a typical mandrel.

In Figure 3 we look at the actual moles of gas pumped in as a function of elapsed time for several different pump frequencies. To determine this we take the actual $\Delta P_{\text {in }}$ 
for each cycle and compute the number of moles of gas this corresponds to, and then add this up for all of the cycles. Clearly there is an advantage to more cycles per minute even though the $\Delta P_{\text {in }}$ is not as large per cycle. However this has a limit, and there is no reason to go faster than 2 or 3 cycles per minute; given the kinetics of combustion we might want to go even slower. Note that in this example $\left(500{ }^{\circ} \mathrm{C}, 4.0 \mu \mathrm{m}\right.$ hole, imposed external pressure variation between 2.0 and $5.0 \mathrm{~atm}$ of air) at 2.0 cycles per minute it would take about $10 \mathrm{~h}$ to supply enough air to decompose a mandrel, if pure $\mathrm{O}_{2}$ could be used this would be accelerated by a factor of 5 .

What these calculations have demonstrated is that we should be able to deliver adequate air for thermal decomposition of the mandrel in a reasonable amount of time if the decomposition kinetics are sufficiently fast.

\section{Experimental.}

The pyrolysis system (Fig. 4) consists of a temperature-controlled furnace, a tubular pressure vessel with heat exchanger, a sample holder, and gas pressure pulsing control. To achieve pressure variation we initially tried to use a variable volume chamber constructed from a bellows sealed vacuum valve. This approach offered an efficient means of using a range of gas environments for pyrolysis. The gas could be charged into the chamber and pressure cycled by the compression of the bellows. This approach encountered problems in temperature control because we needed to keep the valve components cool while heating the shell to $500^{\circ} \mathrm{C}$. A simpler design was to use a tube furnace. The sample was contained in a tubular pressure vessel with a removable sample holder. The sample holder is made from 0.25 inch diameter stainless steel rod with cylindrical pockets milled into the side to hold capsules. The pockets are about 3 $\mathrm{mm}$ diameter and $3 \mathrm{~mm}$ deep. The shells to be pyrolyzed are loaded into the pocket and then a thin tubular cap is slid over the pockets to prevent the shells from vibrating out during processing. The holder has a thermocouple imbedded to provide accurate temperature measurement of the shells during pyrolysis. The sample holder is inserted into the tubular pressure vessel and sealed with a nickel VCR gasket. Because compressed air is alternately being admitted and expelled from the sample holder, we provided an extra $55 \mathrm{~cm}$ of tubing in the furnace to preheat the air entering the pyrolysis fixture. Alternately opening a solenoid valve and venting provided pressure cycling. The valve was connected to a compressed air source that passed through an air dryer (Hydro Purge II, Alltech). Air pressure was regulated to 60 psi. The solenoid valve was actuated with a timer that allowed continuous operation. The pressure rises to 60 psi in 2 seconds, holds for $30 \mathrm{sec}$, then bleeds down to 20 psi over $30 \mathrm{sec}$ before repeating. These pressures are in excess of the ambient $15 \mathrm{psi}$, thus the pressure the shell sees varies between about 5 and $2 \mathrm{~atm}$. Although the pressure in the tube follows this variation closely, the pressure (and thus the amount of $\mathrm{O}_{2}$ ) in the shell lags and depends upon the rate of gas flow through the drilled hole. For the experiments thus far performed the diameter of the hole has been at the smallest 5-6 $\mu \mathrm{m}$, and the length of these holes (Be wall thickness) from $20 \mu \mathrm{m}$ to more than $160 \mu \mathrm{m}$. Smaller diameter and longer holes will certainly restrict flow further, however calculations show that it is still possible to get sufficient gas in and out of the shell to effect complete decomposition. The pyrolysis heating profile has been typically ramping in $1 \mathrm{~h}$ from room temperature to 500 and holding for $50 \mathrm{~h}$. 


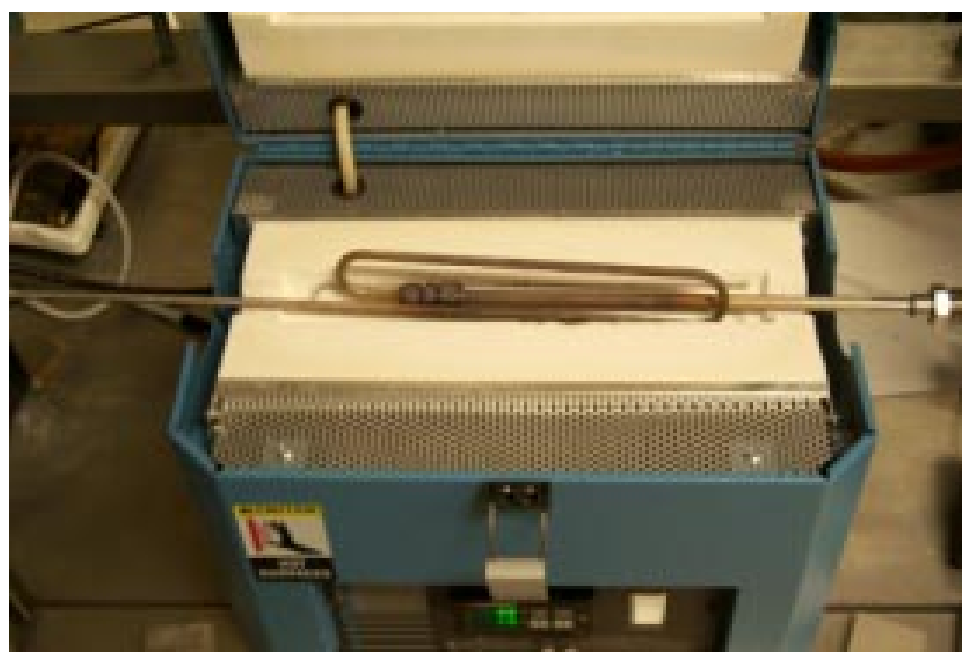

Figure 4. Photo of heat exchanger

\section{Results.}

Attempts to follow the removal of the mandrel by measuring the mass of the shell as a function of time were stymied by a concurrent increase in mass due to Be shell oxidation in the furnace. Thus the primary non-destructive technique that was used was contact radiography, before and after heating. An example of the results for relatively thin shells is shown in Figure 5. On the left is the radiograph of a portion of the wall before pyrolysis. One can see the internal $\sim 14 \mu \mathrm{m}$ thick plastic mandrel, and the $\sim 20 \mu \mathrm{m}$ thick Be layer on top of it. A $~ 6 \mu \mathrm{m}$ hole was laser drilled through the capsule wall. On the right is the same shell after pyrolysis for $35 \mathrm{~h}$ at $450{ }^{\circ} \mathrm{C}$ with pressure cycling between 2 and 5 atm of air once per minute. Clearly the mandrel has been removed. Similar results have been obtained for thick $(>100 \mu \mathrm{m})$ shells, an example is shown in Figure 6.
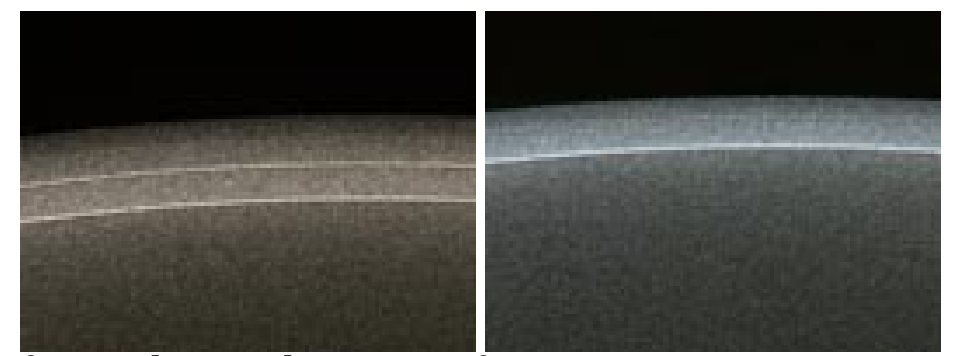

Figure 5. Left, a radiographic view of a $\sim 20 \mu \mathrm{m}$ Be coating on a $\sim 14 \mu \mathrm{m}$ walled plastic mandrel. Right, the same shell after pyrolysis for $35 \mathrm{~h}$ at 450 ${ }^{\circ} \mathrm{C}$ with pressure cycling between 2 and $5 \mathrm{~atm}$ of air once per minute. 


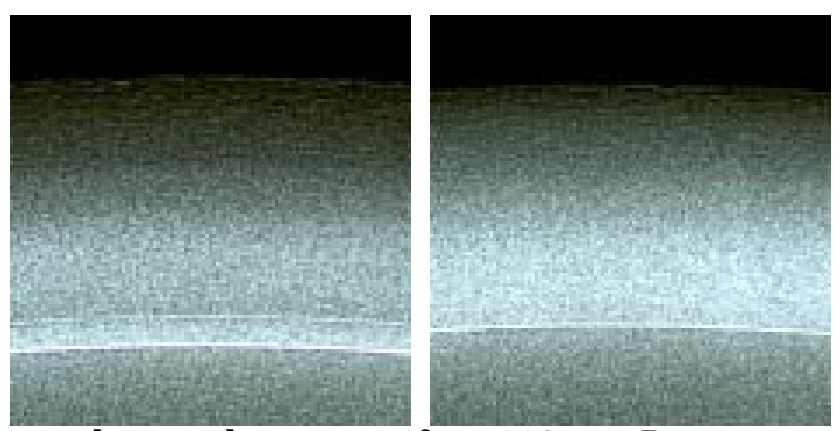

Figure 6. Left, a radiographic view of a $\sim 110 \mu \mathrm{m}$ Be coating on a $\sim 14 \mu \mathrm{m}$ walled plastic mandrel. Right, the same shell after pyrolysis for $150 \mathrm{~h}$ at $500{ }^{\circ} \mathrm{C}$ with pressure cycling between 2 and $5 \mathrm{~atm}$ of air once per minute.

\section{Discussion.}

Although we have demonstrated a mandrel removal process, work needs to be done to optimize the process, particularly with regard to the minimum time necessary for complete removal and related oxidation questions.

Inspection of the internal surfaces of some of our shells shows a field of $\sim 1 \mu \mathrm{m}$ or less "specks" of material, an example SEM image is shown in Figure 7. Analysis of the specks by secondary Ion Mass Spectroscopy (SIMS) shows them to be carbon based, and AFM measurements show them to be at most 15-20 nm high, most are considerably less. A few larger $(0.5 \mu \mathrm{m}$ high $)$ defects have been seen. It is likely that these deposits represent some very small degree of graphitization of the plastic mandrel during pyrolysis, since graphite is resistant to oxidation at $500{ }^{\circ} \mathrm{C}$. Studies using higher temperatures to enhance combustion and more frequent cycling and/or the use of pure $\mathrm{O}_{2}$ to increase the supply of $\mathrm{O}_{2}$ are underway.

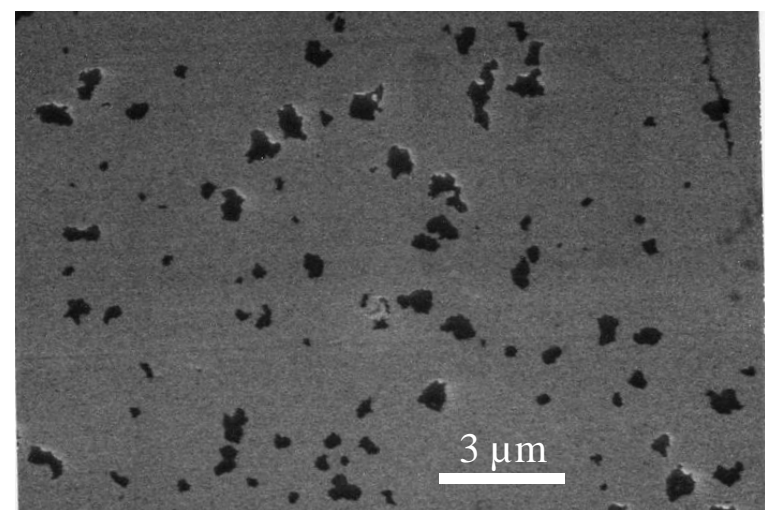

Figure 7. SEM image of the inside of a Be shell that has had its mandrel removed.

The other concern is the degree of oxidation the Be shell undergoes during the pyrolysis process. The oxidation rate on full density Be foils at elevated temperatures has been reported by Gulbransen and $A_{n d r e w}{ }^{8}$ in a 1950 paper. They find that the rate of mass gain follows a parabolic rate eq: 


$$
W^{2}=K t+C
$$

where $W$ is the weight gain in $\mu \mathrm{g} / \mathrm{cm}^{2}, t$ is the time in minutes, and $K$ and $C$ are constants. This parabolic form is common for surface reactions and is due to the rate determining step being the diffusion of Be through the growing oxide coating. Supporting this view is that the rate of reaction is independent of the pressure of $\mathrm{O}_{2}$ gas. There is data for $500{ }^{\circ} \mathrm{C}$ and $0.1 \mathrm{~atm}$ of $\mathrm{O}_{2}$. One can fit their data above 1200 minutes $(20 \mathrm{hrs})$ with the following expression:

$$
W^{2}=.0208 \cdot t+18.3
$$

which gives values of $W$ for 1,2 , and 3 days of about $7.0,8.8$, and $10.4 \mu \mathrm{g} / \mathrm{cm}^{2}$. The equivalent thickness of a pure $\mathrm{BeO}\left(\rho=3.0 \mathrm{~g} / \mathrm{cm}^{3}\right)$ layer is 37,46 , and $54 \mathrm{~nm}$, respectively, certainly not enough to affect the performance of the capsules. However this was for full density Be foil, not sputtered Be capsules. Initial studies of mass gain indicated about a 100 fold increase in the degree of oxidation. However this was later found to be for a very porous coating with density as low as $80 \%$ of full density Be. Radiographic analysis showed that oxidation was occurring deep into the shell wall, and thus the porosity was effectively increasing the surface area of the shell. We plan to continue these studies on the near full density sputtered shells now being produced.

\section{Conclusion.}

We have developed an engineering model for removing the plastic mandrel from the inside of sputtered Be shells. First a small ( $\sim 4$ to $5 \mu \mathrm{m}$ diameter) laser drilled hole is created through the wall, then $500{ }^{\circ} \mathrm{C}$ air is forced in and out of the shell by cycling the external pressure. At these temperatures the plastic mandrel is combusted to $\mathrm{CO}_{2}$ and $\mathrm{H}_{2} \mathrm{O}$ gas. The approach has been tested on a number of shells and found to be effective. Remaining issues include the complete removal of small (1 $\mu \mathrm{m}$ wide by 10$20 \mathrm{~nm}$ high) deposits of carbon-based material that are left on the shell interior, and a more complete evaluation of the degree of beryllium oxidation that takes place during the process.

\section{Acknowledgement}

The authors thank Paul Armstrong for laser drilling, Kelly Youngblood, Charlotte King, and Kristie Segraves for radiography, and Janelle Gunther for SIMS analysis. This work was performed under the auspices of the U.S. Department of Energy by the University of California Lawrence Livermore National Laboratory under contract No. W-7405-Eng-48

\section{References}

${ }^{1}$ G. H. Miller, E. I. Moses, and C. R. Wuest, "The National Ignition Facility," Opt. Eng. 43, 2841 (2004).

${ }^{2}$ S. W. Haan, et al., "Update on NIF Indirect Drive Ignition Target Fabrication Specifications," Fusion Sci. Technol. 45, 69 (2004). See also S. W. Haan, "title," this issue for an update on the current design. 
${ }^{3}$ R. McEachern, C. Alford, R. Cook, D. Makowiecki, and R. Wallace, "Sputter Deposited Be Ablators for NIF Target Capsules," Fusion Technol. 31, 435 (1997). See also H. Xu, J, Wall, A. Nikroo, R. Doerner, and M. Baldwin, "Be Coatings on Spherical Surface for NIF Target Development," and M. McElfresh, others, "title," in this issue.

${ }^{4}$ For Be the linear expansion coefficient, $\alpha_{L}=\frac{1}{L} \cdot \frac{d L}{d T}$, where $L$ is length and $T$ is temperature, is $1.1 \times 10^{-5} \mathrm{~K}^{-1}$ at $293 \mathrm{~K}$ (American Institute of Physics Handbook, $3^{\text {rd }} e d$, edited by D. E. Gray, McGrawHill, New York, 1973, p 4-121), while typical ambient temperature measures for polymers below their glass transition temperature are about $1 \times 10^{-4} \mathrm{~K}^{-1}$, (J. E. Mark, Physical Properties of Polymers Handbook, American Institute of Physics, Woodbury, New York, 1996, p 85); the listed values are $\alpha_{\rho}$, a division by 3 gives $\alpha_{L}$ )

${ }^{5}$ P. Armstrong, others, "Drilling paper," this issue.

${ }^{6}$ B. W. McQuillan, A. Nikroo, D. A. Steinman, F. H. Elsner, D. G. Czechowicz, M. L. Hoppe, M. Sixtus, and W. J. Miller, "The PaMS/GDP Process for Production of ICF Target Mandrels," Fusion Technol. 31, 381 (1997).

${ }^{7}$ Handbook of Chemistry and Physics, 78th ed, edited by David R. Lide, CRC Press, New York, 1997, p. 6-14 and 6-194. The data on these pages gives the viscosity of air, $\mathrm{O}_{2}$ and $\mathrm{N}_{2}$ as a function of temperature in units of $\mu \mathrm{Pa}$-s. For air the data only goes up to $327^{\circ} \mathrm{C}$, but for $\mathrm{N}_{2}$ goes up above $600{ }^{\circ} \mathrm{C}$. To deal with the higher temperatures we've fit the air data with a simple quadratic: $\eta($ air $)=17.34+$ $0.0477 \mathrm{~T}-0.00002 \mathrm{~T}^{2}$, where $\mathrm{T}$ is in ${ }^{\circ} \mathrm{C}$. The data for $\mathrm{N}_{2}$ was used to check that this kind relatively low temperature fit can be reasonably used at temperatures up to $600{ }^{\circ} \mathrm{C}$.

${ }^{8}$ E. A. Gulbransen and K. F. Andrew, "The Kinetics of the Reaction of Beryllium with Oxygen and Nitrogen and the Effect of Oxide and Nitride Films on its Vapor Pressure," J. Electrochem. Soc. 97, 383 (1950). 